\title{
Glass Transition Behaviors of Random and Block Copolymers and Polymer Blends of Styrene and Cyclododecyl Acrylate. I. Glass Transition Temperatures
}

\author{
Hiroshi Daimon, Hiroyuki Okitsu, ${ }^{*}$ and Ju Kumanotani \\ Institute of Industrial Science, University of Tokyo, \\ 22-1, Roppongi 7-chome, Minato-ku, Tokyo, Japan.
}

(Received December 13, 1974)

\begin{abstract}
Glass transition temperatures have been studied for the random and block copolymers of styrene and cyclododecyl acrylate.

The random copolymers showed a single glass transition temperature, which provided a concave glass transition temperature-composition curve. This concave relationship was fairly well represented by the modified Gibbs-Dimarzio equation of Uematsu and Honda, which includes the influence of the specific character of cyclododecyl acrylate as a monomeric unit.

Each of the block copolymers as well as the blends of their component homopolymers showed two separated glass transition temperatures corresponding to the respective ones of poly(cyclododecyl acrylate) and polystyrene; these were independent of the total composition, owing to the incompatibility of the components.

KEY WORDS Cyclododecyl Acrylate/Styrene / Random Copolymer/ Block Copolymer / Polymer Blend / Glass Transition Temperature / DSC / Modified Gibbs-Dimarzio Equation / Stiffness Energy / Sequential Distribution /
\end{abstract}

There have been numerous studies on the glass transition temperatures for various copolymer systems. ${ }^{1-3}$ The relationships between glass transition temperatures and compositions for random copolymers have been expressed by several theoretical and empirical equations, such as the Gordon-Taylor, ${ }^{4}$ the Fox,${ }^{5}$ and the GibbsDimarzio equations. ${ }^{6}$ However, these expressions do not take into account the influences of adjacent dissimilar monomeric units on the steric and energetic terms in the copolymer backbones.

Recently, some authors ${ }^{7-11}$ have pointed out the deviations from these equations for various random copolymers. Uematsu and $\mathrm{Honda}^{8,9}$ proposed a modified Gibbs-Dimarzio equation containing a parameter of chain stiffness energy of a dissimilar monomeric unit-linkage in copolymers. On the other hand, Johnston ${ }^{10}$ modified the Fox relationship by considering sequential distributions in copolymers.

* Present address: Institute of Industrial Science, Teijin Co. Ltd., Hinode 2-1, Iwakuni, Japan.
In the preceding papers, ${ }^{12,13}$ we reported that the radical copolymerization of cyclododecyl acrylate with styrene or acrylonitrile produced random-type copolymers, in which the characteristic reactivity of cyclododecyl acrylate was attributed to the specific characteristics of its cyclododecyl group, a large molar volume and cohesive energy. This reactivity would result in the peculiar structures of the copolymers.

A block copolymer presents a contrast to a random copolymer in the sequential distributions. Graham, et al. ${ }^{14}$ noted that isopropyl acrylate could give a AB-type block copolymer with living polystyrene anions initiated by $n$ butyllithium-tetrahydrofuran, but other acrylates such as ethyl and cyclohexyl acrylates had not polymerized well. In our laboratory, however, a AB-type block copolymer of cyclododecyl acrylate and styrene could be obtained according to the Graham's method.

In this paper, we report the glass transition temperatures of the prepared random and block copolymers of styrene and cyclododecyl acrylate, 


\section{Styrene-Cyclododecyl Acrylate Copolymers}

as investigated by DSC. The relationship between glass transition temperatures and compositions of the random copolymers was treated with the empirical equations. The modified GibbsDimarzio equation by Uematsu and Honda gave a satisfactory explanation for the experimental results. On the other hand, the block copolymers as well as their component polymer blends had two glass transition temperatures which were independent of composition.

\section{EXPERIMENTAL}

\section{Preparation of Random Copolymers}

We previously reported ${ }^{13}$ that the free radical copolymerization of styrene (St) and cyclododecyl acrylate (CDA) provided random copolymers: The monomer reactivity ratios, $r_{\mathrm{B}}$ and $r_{\mathrm{A}}$, are 0.6 and $0.33\left(M_{\mathrm{A}}=\mathrm{CDA}\right)$, respectively; their product is 0.20 . In this study, poly (cyclododecyl acrylate) (PCDA) and three kinds of random St-CDA copolymers (A-1, A-2, and A-3) were prepared in the presence of $\alpha, \alpha^{\prime}$-azobisisobutylonitrile (AIBN) in benzene at $60^{\circ} \mathrm{C}$ with the variation in molar ratios of monomers for the times giving 10-15-\% conversions. The obtained copolymers were precipitated twice with a benzene-methanol system and dried in vacuo at $50^{\circ} \mathrm{C}$ for several days.

In Table I, the composition, density, and number-average molecular weight $\left(M_{n}\right)$ for the random copolymers are presented. The composition was determined by carbon and hydrogen analyses, and the density was measured at $20^{\circ} \mathrm{C}$ by the flotation method with aqueous solutions of calcium chloride. The number-average molecular weight $\left(M_{n}\right)$ was determined by GPC with a Waters Model R-4 as based on a calibration curve of monodisperse polystyrenes (Waters
Table I. Composition, density, and molecular weight of random copolymers of styrene (St) and cyclododecyl acrylate (CDA)

\begin{tabular}{lcccc}
\hline Sample & $\begin{array}{c}\text { Mole fraction } \\
\text { of CDA in } \\
\text { copolymer }\end{array}$ & $\begin{array}{l}\text { Density } \\
\text { at } 20^{\circ} \mathrm{C}\end{array}$ & $M_{n}$ & $M_{w} / M_{n}$ \\
\hline A-1 & 0.194 & 1.047 & $4.31 \times 10^{4}$ & 1.56 \\
A-2 & 0.514 & 1.048 & $7.33 \times 10^{4}$ & 1.56 \\
A-3 & 0.776 & 1.049 & $13.7 \times 10^{4}$ & 1.79 \\
PCDA & 1.000 & 1.050 & $18.4 \times 10^{4}$ & 1.94 \\
\hline
\end{tabular}

Associates Inc.).

Preparation of Block Copolymers

According to the method by Graham, et al., ${ }^{14}$ the block copolymers, Z-1 and Z-2, were produced by the addition of CDA to living polystyrene anions initiated with $n$-butyllithium-tetrahydrofuran in toluene as solvent under highly reduced pressure $\left(10^{-4} \mathrm{mmHg}\right)$ at room temperature. The obtained block copolymers were purified and dried by the same methods as used in the case of the random copolymers. Identity of these block copolymers was confirmed by TLC with silica gel and benzene as an eluting solvent (the details of the preparation will be published elsewhere).

The composition, density, and $M_{n}$ of these block copolymers are listed in Table II. Table II also presents $M_{n}$ of polystyrene (PSt) prepared under the same conditions as in the synthesis of the block copolymer without the addition of CDA, which would correspond to the PSt block component of the copolymer. These values were close to the $M_{n}$ values expected from the molar ratios of St monomer and initiator.

The IR spectra of the block copolymers were in coincidence with those of the random copolymers. ${ }^{13}$ In addition, the densities of these co-

Table II. Composition, density, and molecular weight of block copolymers of styrene (St) and cyclododecyl acrylate (CDA)

\begin{tabular}{|c|c|c|c|c|c|c|}
\hline \multicolumn{5}{|c|}{ Block copolymer } & \multicolumn{2}{|c|}{$\mathrm{PSt}^{\mathrm{b}}$} \\
\hline Sample & $\begin{array}{l}\text { Mole fraction of CDA } \\
\text { in copolymer }\end{array}$ & Density at $20^{\circ} \mathrm{C}$ & $M_{n}$ & $M_{w} / M_{n}$ & $M_{n}$ & $\boldsymbol{M}_{w} / \boldsymbol{M}_{n}$ \\
\hline$Z-1$ & $0.098(0.199)^{\mathrm{a}}$ & 1.048 & $13.1 \times 10^{4}$ & 1.37 & $9.02 \times 10^{4}$ & 1.35 \\
\hline $\mathrm{Z}-2$ & $0.151(0.290)^{\mathrm{a}}$ & 1.049 & $1.28 \times 10^{4}$ & 1.59 & $0.66 \times 10^{4}$ & 1.07 \\
\hline
\end{tabular}

a Weight fraction of CDA in copolymer.

b Prepared under the same conditions without the addition of CDA. 
polymers in Tables I and II changed little with the variation in sequential structures but depended mainly on the compositions.

However, the block copolymers as well as the PSt-PCDA blends were molded into whitish, opaque films under reduced pressure at $160-$ $195^{\circ} \mathrm{C}$, in contrast to the colorless, transparent films of the random copolymers.

The polymer blends, Blend-1 (29.0-wt $\%$ PCDA-71.0-wt $\%$ PSt) and Blend-2 (50.0-wt $\%$ PCDA-50.0-wt\% PSt), were respectively obtained by pouring the benzene solution of a mixture of PSt $\left(M_{n}=9.0 \times 10^{4}\right)$ prepared with $n$ butyllithium and PCDA $\left(M_{n}=1.8 \times 10^{5}\right)$ with AIBN into methanol.

\section{DSC Measuring Procedures}

Glass transition temperatures $\left(T_{\mathrm{g}}\right)$ were measured by DSC with a Perkin-Elmer Model DSC$1 \mathrm{~B}$ at a scanning rate of $32^{\circ} \mathrm{C} / \mathrm{min}$ under nitrogen streaming. For the measurements, a sample $(6-8 \mathrm{mg})$ which had been heated up to 120 $195^{\circ} \mathrm{C}$ was then quenched to $0^{\circ} \mathrm{C}$ in the apparatus. A thermogram was run, and $T_{\mathrm{g}}$ was determined as the temperature at which a endothermic peak started in the DSC thermogram. ${ }^{15}$

\section{RESULTS AND DISCUSSION}

Glass Transition Temperatures of Random St$C D A$ Copolymers

The DSC thermograms for PSt $\left(M_{n}=9.0 \times 10^{4}\right)$, PCDA $\left(M_{n}=1.8 \times 10^{5}\right)$, and random St-CDA copolymers, A-1, A-2, and A-3, are presented in Figure 1. Each of the random copolymers exhibited a single $T_{\mathrm{g}}$ as listed in Table III. Figure 2, shows a concave $T_{\mathrm{g}} v s$. composition curve for the random copolymers.

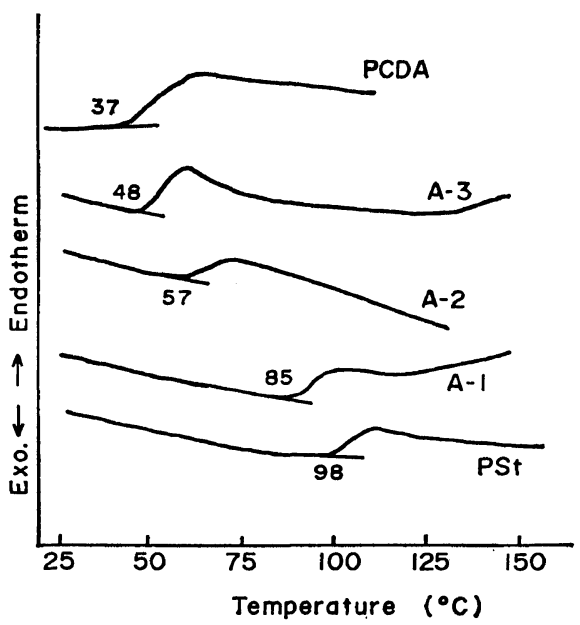

Figure 1. DSC thermograms of PCDA, PSt, and random $\mathrm{St}-\mathrm{CDA}$ copolymers (A-1, A-2, and A-3).

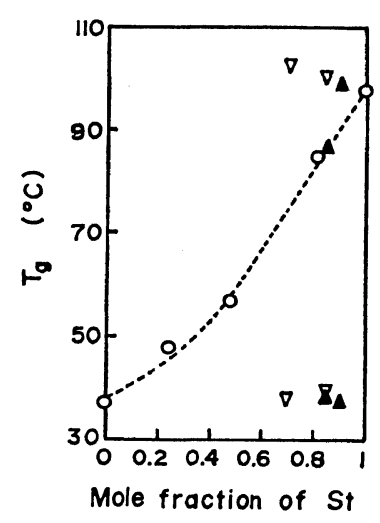

Figure 2. Relationship between glass transition temperatures $\left(T_{\mathrm{g}}\right)$ and compositions of $\mathrm{St}-\mathrm{CDA}$ copolymers: (O) random copolymers; (A) block copolymers; $(\nabla)$ polymer blends.

Table III. Glass transition temperatures of random copolymers of styrene ( $\mathrm{St}$ ) and cyclododecyl acrylate (CDA)

\begin{tabular}{|c|c|c|c|c|c|c|c|c|c|c|}
\hline \multirow{3}{*}{ Sample } & \multirow{3}{*}{$\begin{array}{l}\text { Mole fraction of } \\
\text { CDA in } \\
\text { copolymer }\end{array}$} & \multirow{3}{*}{$\underset{{ }^{\circ} \mathrm{K}\left(\text { obsd }\left({ }^{\circ} \mathrm{C}\right)\right.}{T}$} & \multicolumn{8}{|c|}{$T_{\mathrm{g}}($ calcd $),{ }^{\circ} \mathrm{K}$} \\
\hline & & & \multirow[t]{2}{*}{ Fox } & \multirow[t]{2}{*}{ Wood } & \multirow[t]{2}{*}{ Johnston } & \multicolumn{5}{|c|}{$\begin{array}{l}\text { Modified Gibbs-Dimarzio eq by } \\
\text { Uematsu and Honda }\end{array}$} \\
\hline & & & & & & Case A & Case B & Case C & Case D & Case $\mathrm{E}$ \\
\hline$A-1$ & $0.192(0.355)^{\mathrm{a}}$ & $358(85)$ & 348 & 354 & 356 & 352 & 359 & 352 & 356 & 357 \\
\hline A-2 & $0.514(0.708)^{a}$ & 330 & 327 & 335 & 340 & 333 & 327 & 330 & 332 & 330 \\
\hline A-3 & $0.763(0.880)^{\mathrm{a}}$ & $321(48)$ & 317 & 322 & 325 & 325 & 314 & 323 & 320 & 320 \\
\hline
\end{tabular}

a Weight fraction of CDA in copolymer. 
There have been some theoretical and empirical equations $s^{4-7}$ concerning the relationship between the glass transition temperatures and compositions of random copolymers. They can be expressed by the following Wood equation: ${ }^{7}$

$$
W_{\mathrm{A}}\left(T_{\mathrm{g}}-T_{\mathrm{gA}}\right)+K W_{\mathrm{B}}\left(T_{\mathrm{g}}-T_{\mathrm{gB}}\right)=0
$$

where $T_{\mathrm{g}}$ is the glass transition temperature of a copolymer containing the weight fractions, $W_{\mathrm{A}}$ and $W_{\mathrm{B}}$, of two monomeric units, $\mathbf{A}$ and $\mathbf{B}$, and $T_{\mathrm{gA}}$ and $T_{\mathrm{gB}}$ are the glass transition temperatures of the homopolymers, respectively. The GordonTaylor equation ${ }^{4}$ requires the constant, $K=$ $\Delta \beta_{B} / \Delta \beta_{A}$, in eq 1 where $\Delta \beta_{A}$ or $\Delta \beta_{B}$ is the difference between the expansion coefficients of the rubbery and glassy states of homopolymer A or B. On the other hand, the Gibbs-Dimarzio equation $^{6}$ defines $K=\alpha_{\mathrm{B}} M_{\mathrm{A}} / \alpha_{\mathrm{A}} M_{\mathrm{B}}$ in eq 1 where $\alpha_{\mathrm{A}}$ or $\alpha_{\mathrm{B}}$ is the number of rotatable bonds of a monomeric unit having the molecular weight, $M_{\mathrm{A}}$ or $M_{\mathrm{B}}$. For the special case where $K=$ $T_{\mathrm{gA}} / T_{\mathrm{gB}}$, eq 1 reduces to the Fox relationship. ${ }^{5}$

As easily confirmed, the Fox equation did not hold for the random St-CDA copolymers (see Table III). Equation 1 calls for linearity in a plot of $T_{\mathrm{g}}$ against $\left(T_{\mathrm{gB}}-T_{\mathrm{B}}\right)\left(W_{\mathrm{B}} / W_{\mathrm{A}}\right)$ with a slope of $K$, and further in a plot of $T_{\mathrm{g}}$ against $\left(T_{\mathrm{g}}-T_{\mathrm{gA}}\right)\left(W_{\mathrm{A}} / W_{\mathrm{B}}\right)$ with a slope of $-1 / K{ }^{7}$ From Figure 3, since these plots for the random StCDA copolymers deviated somewhat from the linear relations, the experimental coefficient $\left(K_{e}\right)$ was approximately estimated to be 1.54. Actually,

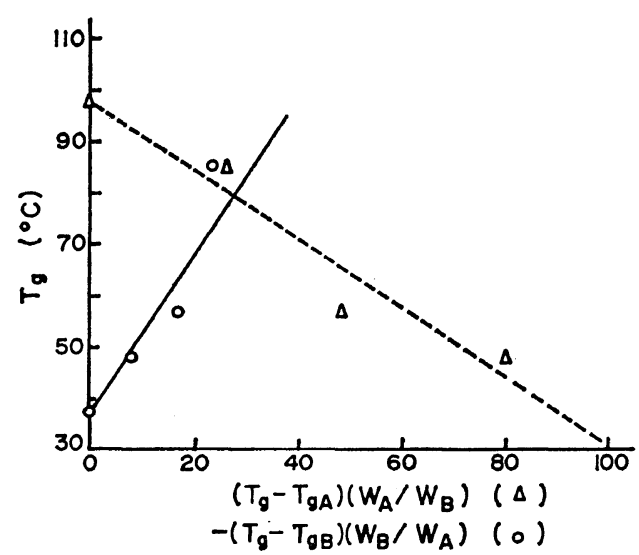

Figure 3. Plots of $T_{\mathrm{g}} v_{s} .\left(T_{\mathrm{g}}-T_{\mathrm{gA}}\right)\left(W_{\mathrm{A}} / W_{\mathrm{B}}\right)$ and $T_{\mathrm{g}} v s .-\left(T_{\mathrm{g}}-T_{\mathrm{gB}}\right)\left(W_{\mathrm{B}} / W_{\mathrm{A}}\right)$ for random $\mathrm{St}-\mathrm{CDA}$ copolymers. the $T_{\mathrm{g}}$ 's calculated by assuming $K=K_{\mathrm{e}}=1.54$ in eq 1 did not agree with the observed $T_{\mathrm{g}}$ 's as given in Table III. Accordingly, neither eq 1 nor the Gordon-Taylor and the Gibbs-Dimarzio equations could satisfactorily express the concave relationship between $T_{\mathrm{g}}$ 's and compositions of the random St-CDA copolymers.

Similar deviations from these equations have been demonstrated for various random copolymers. ${ }^{7-11}$ These expressions do not take into account the influences of adjacent dissimilar monomeric units on steric and energetic terms in copolymer backbones. Therefore the deviation may be attributable to the different contributions of monomeric units in $\mathbf{A}-\mathbf{B}$ bond to the glass transition temperatures of copolymers from those in $\mathrm{A}-\mathrm{A}$ and $\mathrm{B}-\mathrm{B}$ linkages.

Johnston $^{10}$ proposed a modified Fox relationship for the alternating and random copolymers of $\alpha$-methylstyrene and acrylonitrile, taking into account the probabilities, $P_{\mathrm{AA}}, P_{\mathrm{BB}}, P_{\mathrm{AB}}$, and $P_{\mathrm{BA}}$, of diads as follows:

$$
\begin{aligned}
\left(1 / T_{\mathrm{g}}\right)= & \left(W_{\mathrm{A}} P_{\mathrm{AA}} / T_{\mathrm{gA}}\right)+\left(W_{\mathrm{B}} P_{\mathrm{BB}} / T_{\mathrm{gB}}\right) \\
& +\left(W_{\mathrm{A}} P_{\mathrm{AB}}+W_{\mathrm{B}} P_{\mathrm{BA}}\right) / T_{\mathrm{gAB}}
\end{aligned}
$$

where $T_{\mathrm{gA}}, T_{\mathrm{gB}}$, and $T_{\mathrm{gAB}}=T_{\mathrm{gBA}}$ denote the glass transition temperatures of homopolymers A, B, and an imaginary alternating copolymer, respectively. These probabilities are calculated by computing the average run number $(R)$ of Harwood and Ritchy ${ }^{16}$ as follows:

$$
P_{\mathrm{AB}}=R / 200 f_{\mathrm{A}}, \quad P_{\mathrm{AA}}=1.0-P_{\mathrm{AB}}
$$

where $f_{\mathrm{A}}$ and $f_{\mathrm{B}}$ are the mole fractions of $\mathrm{A}$ and $B$ in copolymers. In his paper, no concrete estimation of $T_{\mathrm{gAB}_{\mathrm{B}}}$ was presented. Here we assumed $T_{\mathrm{gAB}}=\left(T_{\mathrm{gA}}+T_{\mathrm{gB}}\right) / 2$ for the random St-CDA copolymers; however, the calculated $T_{\mathrm{g}}$ 's were inconsistent with the observed ones (see Table III). This may indicate that the sequential distributions in these copolymers could not be a dominant factor for the deviation from the empirical equation. Since the inconsistency would be introduced by the faulty assumption of $T_{\mathrm{gAB}}$, this further suggests that $\mathrm{CDA}$ and $\mathrm{St}$ monomeric units would give different contributions to $T_{\mathrm{gAB}}$.

Uematsu and Honda ${ }^{8,9}$ presented a modified Gibbs-Dimarzio equation, estimating the different chain stiffness energy, $\varepsilon_{\mathrm{AB}}$, for $\mathrm{A}-\mathrm{B}$ bond 
from $\varepsilon_{\mathrm{AA}}$ and $\varepsilon_{\mathrm{BB}}$ of the homopolymers as follows:

$$
\begin{gathered}
\varepsilon=f_{\mathrm{AA} \varepsilon_{\mathrm{AA}}+f_{\mathrm{BB}} \varepsilon_{\mathrm{BB}}+f_{\mathrm{AB}} \varepsilon_{\mathrm{AB}}} \\
\left(\varepsilon_{\mathrm{AA}} / k T_{\mathrm{gA}}\right)=\left(\varepsilon_{\mathrm{BB}} / k T_{\mathrm{gB}}\right)=\left(\varepsilon_{\mathrm{AB}} / k T_{\mathrm{gAB}}\right)=\left(\varepsilon / k T_{\mathrm{g}}\right) \\
T_{\mathrm{g}}=f_{\mathrm{AA}} T_{\mathrm{gA}}+f_{\mathrm{BB}} T_{\mathrm{gB}}+f_{\mathrm{AB}} T_{\mathrm{gAB}}
\end{gathered}
$$

where $f_{\mathrm{AA}}, f_{\mathrm{BB}}$, and $f_{\mathrm{AB}}$ are the fractions of the rotational units with corresponding chain stiffness energies. They proposed four cases of A, B, C, and $\mathrm{D}$ according to the modes of triad linkages, in which the fractions can be calculated from the mole fractions and monomer reactivity ratios in copolymers. ${ }^{8}$

Here we tried to divide their case $D$ into two cases $\mathrm{D}$ and $\mathrm{E}$. In case $\mathrm{D}$, a $\mathrm{B}$ monomeric unit producing a higher $T_{\mathrm{gB}}$ of homopolymer was assumed to have always $\varepsilon_{\mathrm{BB}}$ in any linkage-mode in a copolymer. This assumption was applied by Uematsu and $\mathrm{Honda}^{8}$ to various random copolymer systems, for example, methyl acrylate (A) - methyl methacrylate (B) and methyl acrylate (A)-St (B). In contrast to that in case D, each A unit forming a lower $T_{\mathrm{gA}}$ of homopolymer was supposed to have $\varepsilon_{\mathrm{AA}}$ in a copolymer in case E. This case was also suitable for the methyl acrylate (B)-vinylidene chloride (A) and vinyl chloride (B)-vinyl acetate (A) systems as reported by them. ${ }^{8}$

For the random St-CDA copolymers, the $T_{\mathrm{gAB}}$ 's, as determined as the slope of lines for the plots of $T_{\mathrm{g}}$ (obsd $)-\left(f_{\mathrm{AA}} T_{\mathrm{gA}}+f_{\mathrm{BB}} T_{\mathrm{gB}}\right)$ against $f_{\mathrm{AB}}$ in Figure 4 , were $333^{\circ} \mathrm{K}$ in case $\mathrm{A}, 314^{\circ} \mathrm{K}$ in case $\mathrm{B}, 261^{\circ} \mathrm{K}$ in case $\mathrm{C}, 285^{\circ} \mathrm{K}$ in case $\mathrm{D}$, and $341^{\circ} \mathrm{K}$ in case $\mathrm{E}$, respectively. The $T_{\mathrm{g}}$ 's calculated by using these $T_{\mathrm{gAB}}$ 's in eq 4 are listed in Table III. Among them, the calculated $T_{\mathrm{g}}$ 's in cases D and E fitted fairly well to the observed ones; however, in the other cases the values did not match well. These results would indicate that either assumption, from case D or $E$ in the modified Gibbs-Dimarzio equation, could be applicable to the concave $T_{\mathrm{g}} v s$. composition curve for the random St-CDA copolymers. At present we cannot directly determine whether the assumption in case $\mathrm{D}$ or in case $\mathrm{E}$ would be more suitable for this curve. If the completely alternating copolymer could be prepared, we could pick out the appropriate one by comparing the observed $T_{\mathrm{gAB}}$ of the alternat-

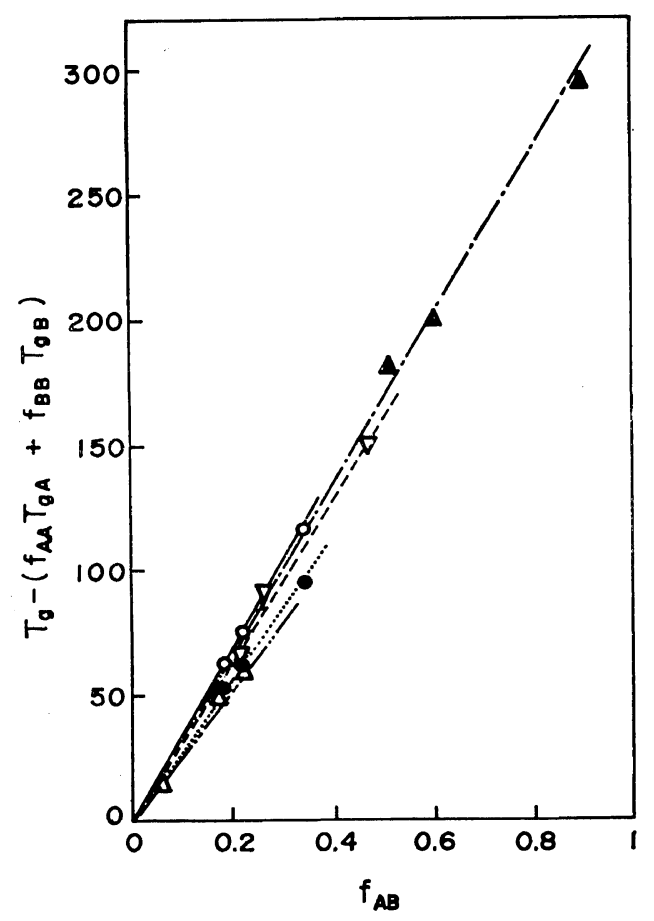

Figure 4. Plots of $T_{\mathrm{g}}$ (obsd) $-\left(f_{\mathrm{AA}} T_{\mathrm{gA}}+f_{\mathrm{BB}} T_{\mathrm{gB}}\right) v s$. $f_{\mathrm{AB}}$ for random $\mathrm{St}-\mathrm{CDA}$ copolymers: $(\boldsymbol{\Lambda})$ in case $\mathrm{A} ;(\nabla)$ in case $\mathrm{B} ;(\triangle)$ in case $\mathrm{C} ;(\boldsymbol{O})$ in case $\mathrm{D}$; (O) in case $\mathrm{E}$.

ing copolymer with the $T_{\mathrm{gAB}}$ 's calculated in these cases.

Recently Hirooka and Kato ${ }^{11}$ reported that the relationships between the glass transition temperatures and compositions for various random copolymers were expressed as three forms, i.e., concave, linear, and convex curves as represented by the modified Gibbs-Dimarzio equation by Uematsu and Honda. They further stated an empirical rule deduced from their experimental results that $T_{\mathrm{gAB}}$ of an alternating copolymer would be lower than that of the corresponding random copolymer with equimolar composition in the case of the concave curve. As presented in Figure 2, the random St-CDA copolymers showed a concave $T_{\mathrm{g}}$-composition curve. According to their empirical rule, the imaginary $T_{\mathrm{gAB}}$ of alternating St-CDA copolymer may be expected to lie below this concave curve. The assumed $T_{\mathrm{gAB}}=285^{\circ} \mathrm{K}\left(12^{\circ} \mathrm{C}\right)$ in case $\mathrm{D}$ would be more in keeping with this rule than $T_{\mathrm{gAB}}=$ $341^{\circ} \mathrm{K}\left(68^{\circ} \mathrm{C}\right)$ in case $\mathrm{E}$. 
As calculated by using $\varepsilon_{\mathrm{BB}}$ of $\mathrm{St}=1.43$ (by Uematsu and $\mathrm{Honda}^{8}$ ) in eq $5, \varepsilon_{\mathrm{AA}}$ of CDA was $1.19 \mathrm{kcal} / \mathrm{mol}$ and $\varepsilon_{\mathrm{AB}}$ was $1.10 \mathrm{kcal} / \mathrm{mol}$ in case $\mathrm{D}$, respectively. In addition, the total chain stiffness energy $(\varepsilon)$ of an imaginary random $\mathrm{St}$ CDA copolymer having $f_{\mathrm{A}}=f_{\mathrm{B}}=0.5$ could be estimated to be $1.28 \mathrm{kcal} / \mathrm{mol}$ in eq 4 . This total stiffness energy may be conveniently expressed as follows:

$$
\varepsilon=\varepsilon_{\mathrm{AA}} z_{\mathrm{A}}+\varepsilon_{\mathrm{BB}} z_{\mathrm{B}}
$$

where $z_{\mathrm{A}}$ and $z_{\mathrm{B}}$ are the fractions of $\varepsilon_{\mathrm{AA}}$ and $\varepsilon_{\mathrm{BB}}$ in $\varepsilon$. In a St-CDA copolymer, St monomeric units can provide rigid skeltons, while CDA units can form flexible backbones in response to $\varepsilon_{B B}$ and $\varepsilon_{A A}$. If the peculiar influences of side groups on the chain stiffness of copolymer backbones could be eliminated, then both $z_{\mathrm{A}}$ and $z_{\mathrm{B}}$ should be 0.5 for the equimolar random copolymer. Actually $z_{\Lambda}$ for CDA units was 0.63 , considerably larger than 0.37 of $z_{\mathrm{R}}$ for $\mathrm{St}$ units.

As reported in our preceding paper, ${ }^{13}$ a CDA monomeric unit can be characterized by its large molar volume $\left(245 \mathrm{~cm}^{3}\right)$, of which cyclododecyl group shares $180 \mathrm{~cm}^{3}$ in comparison with $115 \mathrm{~cm}^{3}$ of a St unit. The great volume of cyclododecyl group may introduce more or less interchain and intramolecular spacing. This would make us suppose that the stiffness of copolymer backbones provided by St units could be considerably decreased by the internal plasticization effect of this side group of a CDA unit to yield the concave $T_{\mathrm{g}}$-composition curve. As an example, we proved that a similar effect for a cyclododecyl group would lead to a lower $T_{\mathrm{g}}\left(81^{\circ} \mathrm{C}\right)$ of poly (cyclododecyl methacrylate) relative to $105^{\circ} \mathrm{C}$ of poly(methyl methacrylate).

Glass Transition Temperatures of Block St-CDA Copolymers and PSt-PCDA Blends

The glass transition behaviors of block copolymers and polymer blends are mainly influenced by the compatibility of their components. ${ }^{2}$ For instance, a block copolymer composed of one homogeneous phase has a single glass transition temperature dependent on the whole composition as found in the block copolymer systems of methyl methacrylate-acrylonitrile by Beevers and White ${ }^{17}$ and styrene- $\alpha$-methylstyrene by Baer. ${ }^{18}$ On the other hand, a copolymer with

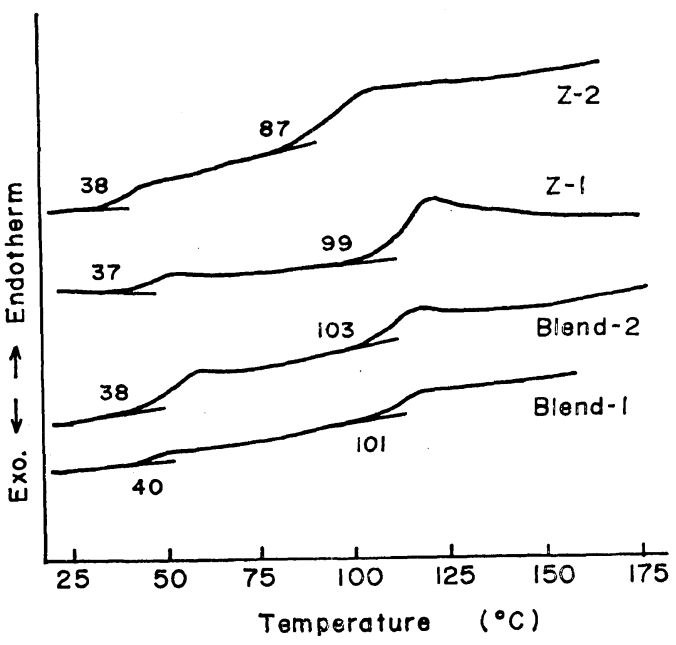

Figure 5. DSC thermograms of block $\mathrm{St}-\mathrm{CDA}$ copolymers (Z-1 and Z-2) and PSt-PCDA blends (Blend-1 and Blend-2).

two heterogenenous phases shows the two glass transition temperatures corresponding to those of the homopolymers, as observed in the butadiene-acrylonitrile rubbers by Ambler. ${ }^{19}$

In the case of PSt and PCDA, their incompatibility could be noticed from the whitish, opaque films of PSt-PCDA blends. Figure 5 shows that the respective PSt-PCDA blends, Blend-1 (29.0-wt \% PCDA) and Blend-2 (50.0-wt $\%$ PCDA), had double, separated endothermic peaks beginning at the same temperatures, $38-40^{\circ} \mathrm{C}$ and $101-103^{\circ} \mathrm{C}$, corresponding to $T_{\mathrm{g}}$ 's of the components, $37^{\circ} \mathrm{C}$ of PCDA $\left(M_{n}=1.8 \times 10^{5}\right)$ and $98^{\circ} \mathrm{C}$ of PSt $\left(M_{n}=9.0 \times 10^{4}\right)$.

Similarly the block St-CDA copolymers, Z-1 and $\mathrm{Z}$-2, were molded into the opaque films and had double endothermic peaks, as shown in Figure 5, for which the $T_{\mathrm{g}}$ 's of the PCDA blocks of both were the same, $37-38^{\circ} \mathrm{C}$, while $T_{\mathrm{g}}$ of the PSt block of Z-2 was $87^{\circ} \mathrm{C}$ lower than $99^{\circ} \mathrm{C}$ of the PSt block of Z-1. The change in $T_{\mathrm{g}}$ 's of these PSt blocks should be mainly ascribed to the difference in their molecular weights, because $T_{\mathrm{g}}$ of the corresponding homopolymer $\left(M_{n}=6.6 \times 10^{3}\right)$ to the PSt block of Z-2 was also $85^{\circ} \mathrm{C}$ lower than $98^{\circ} \mathrm{C}$ of the one $\left(M_{n}=9.0 \times 10^{4}\right)$ to the PSt block of Z-1. Concerning the molecular weight dependence on the glass transition temperatures of polystyrenes, similar results have 
been reported by Fox and Flory ${ }^{20}$ and Hatakeyama and Kanetsuna ${ }^{21}$ that the glass transition temperatures of polystyrenes become considerably lower with a decrease in the molecular weights below $10^{4}$.

Consequently, the respective PCDA blocks and PSt ones of the block copolymers had $T_{\mathrm{g}}$ 's corresponding to those of the homopolymers like the components of the blends. These results would suggest that the components could behave independently in the separated phases owing to their lack of compatibility. As seen in the DSC thermogram for Z-2 in Figure 5, this block copolymer gave a peculiarly increasing slope in the middle of the both $T_{\mathrm{g}}$ 's which may be attributable to a slight interaction of the components. A further study on the glass transition behaviors in the dielectric properties of these copolymers will be reported later.

\section{REFERENCES}

1. N. G. McCrum, B. E. Read, and G. Williams, "Anelastic and Dielectric Effects in Polymer Solids," John Wiley and Sons, London, 1967.

2. "Syntheses and Physical Properties of Copolymers," Chemistry (Suppl. No. 27), T. Kuroda, M. Nagasawa, and Y. Yamashita, Ed., Kagakudojin, Kyoto, January 1967, Chapter II.

3. "Physical Properties of Polymers and Molecular Structures," Chemistry (Suppl. No. 58), M. Nagasawa and Y. Yamashita, Ed., Kagaku- dojin, Kyoto, March 1973, Chapters I-2, I-3, and $\mathrm{I}-4$.

4. M. Gordon and J. S. Taylor, J. Appl. Chem., 2, 493 (1952).

5. T. G Fox, Bull. Amer. Phys. Soc., 1, 123 (1956).

6. E. A. Dimarzio and J. H. Gibbs, J. Polym. Sci., 40, 121 (1959).

7. L. A. Wood, ibid., 28, 319 (1958).

8. I. Uematsu and K. Honda, Rept. Progr. Polym. Phys. Japan, 8, 111 (1960).

9. I. Uematsu, ref 2, Chapter II-4.

10. N. W. Johnston, Macromolecules, 6, 453 (1973).

11. M. Hirooka and T. Kato, J. Polym, Sci., Part $B, 12,31$ (1974); Preprints of SPSJ 23rd Symposium on Macromolecules, Tokyo, 1974, p I249.

12. H. Daimon and J. Kumanotani, Makromol. Chem., in press.

13. H. Daimon and J. Kumanotani, ibid., in press.

14. R. K. Graham, J. R. Panchak, and M. J. Kampf, J. Polym. Sci., 44, 411 (1960).

15. H. Kanetsuna and T. Hatakeyama, ref 3 , Chapter I-3.

16. H. J. Harwood and W. M. Ritchy, J. Polym. Sci., Part B, 2, 601 (1964).

17. R. B. Beevers and E. F. T. White, Trans, Faraday Soc., 56, 1529 (1960).

18. M. Baer, J. Polym. Sci., Part A, 2, 417 (1964).

19. M. R. Ambler, J. Polym. Sci., Polym.-Chem., 11, 1505 (1973).

20. T. G Fox and P. J. Flory, J. Polym. Sci., 14, 315 (1954).

21. T. Hatakeyama and H. Kanetsuna, Kobunshi Kagaku (Chem. High Polymers), 27, 375 (1970). 